\title{
Development of a Methodology Based on Extraction Induced by Emulsion Breaking for Copper Determination in Gasohol by Graphite Furnace Atomic Absorption Spectrometry
}

\author{
Valdinei S. de Souza, ${ }^{\oplus a, b}$ Leonardo S. G. Teixeira, ${ }^{a}$ Maria G. A. Korn, ${ }^{\circledR a}$ \\ Uillian M. F. M. Cerqueira ${ }^{c}$ and Marcos A. Bezerra ${ }^{\circledR *} * c$ \\ ${ }^{a}$ Departamento de Química Analítica, Instituto de Química, Universidade Federal da Bahia, \\ Campus Universitário de Ondina, 40170-115 Salvador-BA, Brazil \\ ${ }^{b}$ Instituto Federal de Educação, Ciência e Tecnologia Baiano, Campus de Santa Inês, \\ 45320-000 Santa Inês-BA, Brazil \\ ${ }^{c}$ Departamento de Ciências e Tecnologias, Universidade Estadual do Sudoeste da Bahia, \\ 45206-190 Jequié-BA, Brazil
}

\begin{abstract}
The development of a method based on extraction induced by emulsion breaking (EIEB) aiming copper determination in gasohol using graphite furnace atomic absorption spectrometry (GF AAS) is reported. Emulsification of the gasohol samples was carried out using nitric acid solution, (1,1,3,3-tetramethylbutyl)phenyl-polyethylene glycol surfactant (Triton X-114), and ultrasound energy. The variables related to the extraction efficiency were optimized by multivariate approaches (two-level factorial fractional design and Doehlert design). The best results were obtained when the emulsion was formed with $5.0 \mathrm{~mL}$ of the sample, $0.200 \mathrm{~mL}$ of $2.4 \mathrm{~mol} \mathrm{~L}^{-1}$ $\mathrm{HNO}_{3}, 0.100 \mathrm{~mL}$ of $10 \%$ Triton X-114 and $10 \mathrm{~min}$ of sonication. A fast and efficient emulsion breaking was performed at $90{ }^{\circ} \mathrm{C}$. A volume of $6.65 \mathrm{~mL}$ of the copper-rich hydroalcoholic phase was extracted, separated from the organic phase and analyzed. Under these conditions, the following analytical characteristics were obtained: 0.61 and $2.0 \mu \mathrm{g} \mathrm{L}^{-1}$ for limits of detection and quantification, respectively; precision (percentage of relative standard deviation, $10 \mu \mathrm{g} \mathrm{L}^{-1}$ ) of

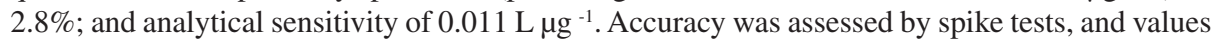
in the range of $95-110 \%$ were achieved. The method was applied in the determination of copper in Brazilian gasoline samples (gasohol with $27 \%$ ethanol).
\end{abstract}

Keywords: copper, gasohol, emulsion breaking, multivariate optimization, GF AAS

\section{Introduction}

Gasohol is the second most-consumed automotive fuel in Brazil, second only to diesel. Its high consumption generates environmental concerns, mainly by the emission of gases and potentially toxic metals into the atmosphere. ${ }^{1}$ Some metals may be present in gasoline, originating from the petroleum or from contamination in the production, transportation, and storage of this fuel. ${ }^{2,3}$ The main sources of copper contamination in gasoline are the metal alloys that make up the production, transport or storage tanks for the fuel. ${ }^{4}$

Anhydrous ethanol that is mixed with the gasoline can also contribute to the presence of copper in the fuel. ${ }^{5-8}$ Currently, the Brazilian National Agency of Petroleum (ANP) establishes a content of 27 or $25 \%\left(\mathrm{v} \mathrm{v}^{-1}\right)$ of ethanol

*e-mail: mbezerra@uesb.edu.br in the gasoline for ordinary gasohol or premium gasohol, respectively. ${ }^{9}$ The levels of metals are not regulated by ANP, except for lead with a maximum value of $5.0 \mathrm{mg} \mathrm{kg}^{-1} \cdot{ }^{10}$ Some metals, such as Fe, Zn, Ni, V and, especially, Cu, can act as catalysts, promoting the oxidation and deterioration of olefins in gasoline that result in the formation of gums, damaging the fuel injection system. ${ }^{11,12}$ Moreover, these metals can cause the poisoning of the Pt- and Pd-based catalysts of automobiles exhaust systems. ${ }^{13,14}$

Analytical strategies have been suggested for the copper determination in gasoline. Generally, a pretreatment step is necessary for sample decomposition or pre-concentration of the analytes. When flame atomic absorption spectrometry (FAAS) was employed, for example, for the determination of $\mathrm{Cu}, \mathrm{Fe}, \mathrm{Ni}$ and $\mathrm{Zn}$ in gasoline, a preconcentration step was necessary, using silica gel modified with 2-aminothiazole groups. ${ }^{15}$ The 3,4-dihydroxybenzoic acid chemically linked 
to a polystyrene resin (XAD-DHB) was employed for preconcentration of $\mathrm{Cu}, \mathrm{Fe}, \mathrm{Pb}$ and $\mathrm{Zn}$, with subsequent acid desorption, for analysis of gasohol by fast sequential flame atomic absorption spectrometry. ${ }^{2}$ In more recent work, ${ }^{13}$ determination of $\mathrm{Cu}, \mathrm{Fe}$, and $\mathrm{Pb}$ in gasohol was proposed applying extraction induced by emulsion breaking for quantification by high-resolution continuous-source flame atomic absorption spectrometry (HR-CS F AAS). The determination of $\mathrm{Cd}, \mathrm{Cr}, \mathrm{Cu}, \mathrm{Pb}$ and $\mathrm{Ni}$ in gasoline by atomic absorption spectrometry with a transverse heated furnace atomizer (THFA) was possible after dilution of the samples in $n$-heptane at $1: 4\left(\mathrm{v} \mathrm{v}^{-1}\right) .{ }^{10}$ The quantification of $\mathrm{Cu}, \mathrm{Mn}, \mathrm{Ni}$, and $\mathrm{Sn}$ in samples of gasoline was also possible by coupling electrothermal vaporization with inductively coupled plasma mass spectrometry (ETV-ICP-MS), in order to minimize problems related to the introduction of organic solvents into plasma. ${ }^{8}$

Extraction induced by emulsion breaking (EIEB) is an extraction technique based on the formation of a micellar medium. Emulsion breaking is a phenomenon characterized by the segregation of immiscible phases that result from emulsion destabilization, obtaining two clearly separated liquid phases. After the phase separation, the analyte, which was present in the original matrix, is found to have been transferred to the aqueous phase. ${ }^{16}$

The following advantages are highlighted when EIEB is used in the analysis of samples with a high content of organic substances: efficient transfer of the analytes from a more complex matrix to a simpler analytical matrix, a sample digestion step that requires more time and more drastic conditions is unnecessary, use of low-cost reagents, and simplicity and operational ease of extraction. ${ }^{17,18}$ It was demonstrated that the use of ultrasonic energy makes the emulsification process more efficient. ${ }^{19}$ This high efficiency is due to the process of energy transfer and agitation promoted by processes of nucleation, growth, and the collapse of transient bubbles in liquids exposed to low-frequency ultrasonic waves $\left(<1 \mathrm{MHz}\right.$ ), called cavitation. ${ }^{20}$

Even with all the advantages presented in the methods for determining metals in gasoline, there are few studies that describe the possibility of applying an external calibration. For routine analysis, external calibration can provide a higher analytical frequency.

Aiming to overcome the difficulties found in the analysis of volatile and high organic content samples such as gasoline, this work proposes a fast and reliable method for the extraction and determination of copper in gasohol using a procedure based on emulsification assisted by ultrasound energy followed by emulsion breakage-induced extraction. A two-level fractional factorial (used for screening variables) and a Doehlert designs were applied to optimize the variables of interest. The high-resolution continuous source atomic graphite furnace absorption spectrometry (HR-CS GF AAS) technique was applied.

\section{Experimental}

\section{Instrumentation}

Copper quantifications were carried out using a ContrAA 700 (Analytik Jena AG, Jena, Germany) high-resolution continuous source graphite furnace atomic absorption spectrometer (HR-CS GF AAS), a graphite furnace autosampler (MPE 60 model, Analytik Jena AG, Jena, Germany) coupled to a xenon short-arc lamp presenting a potency of $300 \mathrm{~W}$ (XBO 301, GLE, Berlin, Germany) operating in hot spot mode as a source of continuous radiation. Optical part presents a coupled charge detector (CCD) and a compact double Echelle monochromator. Integrated platform pyrolytically coated graphite tubes were used as atomizer. Argon of high purity $(99.99 \%)$ was used for the purging and protection of the graphite tube. The heating program for copper determination is given in Table 1. Analytical signals (integrated absorption peak area) were acquired, treated and stored by the Aspect CS 2.1.2.0 software (Analytik Jena AG, Jena, Germany). Data were obtained by selecting three pixels. Measurements were performed at the highest sensitivity wavelength indicated by the equipment supplier for copper $(\lambda=324.7540 \mathrm{~nm})$.

Table 1. Heating program used to determine copper in gasohol by HR-CS GF AAS after extraction by the proposed method

\begin{tabular}{lcccc}
\hline Step & $\begin{array}{c}\text { Temperature / } \\
{ }^{\circ} \mathrm{C}\end{array}$ & $\begin{array}{c}\text { Ramp / } \\
\left({ }^{\circ} \mathrm{C} \mathrm{s}^{-1}\right)\end{array}$ & Hold / s & $\begin{array}{c}\text { Argon flow } \\
\text { rate / } \\
\left(\mathrm{mL} \mathrm{min}^{-1}\right)\end{array}$ \\
\hline Drying 1 & 80 & 6 & 20 & 250 \\
Drying 2 & 90 & 3 & 20 & 250 \\
Drying 3 & 110 & 5 & 10 & 250 \\
Pyrolysis 1 & 350 & 50 & 20 & 250 \\
Pyrolysis 2 & 1100 & 300 & 10 & 250 \\
Gas adaptation & 1100 & 0 & 5 & 0 \\
Atomization & 2500 & $\mathrm{FP}$ & 8 & 0 \\
Clean & 2600 & 500 & 4 & 250 \\
\hline
\end{tabular}

FP: full power.

A Cristofoli (Campo Mourão, Paraná, Brazil) ultrasound bath (power $0.17 \mathrm{~W}$ ) operated at $42 \mathrm{kHz}$ ultrasound frequency was used for sonication of the samples and to promote the surfactant solubilization in $\mathrm{HNO}_{3}$ solution. A heating bath equipment with controlled temperature (range of $50-120^{\circ} \mathrm{C}$ ), with stability of $\pm 2{ }^{\circ} \mathrm{C}$, was used. 


\section{Solutions and reagents}

All experiments were carried out using reagents of analytical purity grade. A purification system (Purelab Classic model, High Wycombe, UK) was used to obtain ultrapure water. Glasswares were immersed in $10 \%\left(\mathrm{v} \mathrm{v}^{-1}\right)$ $\mathrm{HNO}_{3}$ solution (Êxodus Científica, São Paulo, Brazil) during $24 \mathrm{~h}$ aiming their decontamination, posteriorly rinsed with deionized water and dried at the air. Copper aqueous solutions were prepared by appropriate dilutions of a standard solution (Merck, Kenilworth, NJ, USA) at a concentration of $1000 \mathrm{mg} \mathrm{L}^{-1}$ in solution of $1 \%\left(\mathrm{v} \mathrm{v}^{-1}\right)$ $\mathrm{HNO}_{3}$. Hydrocarbon oil organic standard WM-215X, $50 \mathrm{\mu g} \mathrm{g}^{-1}$ (AccuStandard, New Haven, USA) was also used in these studies. A $10 \%\left(\mathrm{v} \mathrm{v}^{-1}\right)(1,1,3,3$-tetramethylbutyl) phenyl-polyethylene glycol surfactant (Triton X-114, Vetec, Rio de Janeiro, Brazil) surfactant solution and a $10 \%\left(\mathrm{v} \mathrm{v}^{-1}\right)$ $\mathrm{HNO}_{3}$ (Êxodo, São Paulo, Brazil) solution were made by dilution of the reagent in aqueous medium. A hexane (Êxodo Ciêntifica, Brazil) and octane (Merck, Germany) mixture (1:1) in volume was used to simulate the blank of the gasohol.

\section{Samples}

Five samples of common gasohol and one sample of gasohol containing additives were collected in high-density polyethylene vessels certified by Inmetro, ${ }^{21}$ at different fuel stations localized in the cities of Jequié, Jaguaquara and Salvador (Bahia State, Brazil).

\section{Pyrolysis and atomization curves}

The thermal behavior of copper has been studied by plotting its pyrolysis and atomization curves. Pyrolysis curve was obtained setting the atomization temperature at $2000^{\circ} \mathrm{C}$. Then, the temperature was studied in the range of 700 to $1300{ }^{\circ} \mathrm{C}$. After the optimum pyrolysis temperature has been selected, it was set. Then, to obtaining the atomization curve, temperatures were varied from 1800 to $2800^{\circ} \mathrm{C}$. These measurements were registered as integrated absorbance of the gasohol sample with the addition of organic standard, for a final concentration of $20 \mu \mathrm{g} \mathrm{L}^{-1}$, and after submission to the EIEB procedure.

\section{Multivariate optimization}

Aiming to optimize the EIEB procedure, two multivariate designs have been applied: ( $i$ ) $2^{4-1}$ two-level fractional factorial and (ii) Doehlert matrix. Experiments were carried out in random order making use of blended samples of gasohol doped with solutions of the organic standard and submitted to the EIEB procedure. Two-level fractional factorial design was performed to investigate which variables (inside the established experimental field) are significant for the EIEB procedure. Table 2 presents the levels established for the studied variables and Table 3 the experimental matrix of the fractional factorial design and responses (integrated absorbances). Table 4 presents the Doehlert matrix used to study the variables: Triton X-114 surfactant concentration (SC) between 0.1 and $0.9 \%\left(\mathrm{v} \mathrm{v}^{-1}\right)$,

Table 2. Two-level fractional factorial design $2^{4-1}$ used in the screening of variables involved in the copper extraction induced by emulsion breaking: levels established for the studied variables

\begin{tabular}{lcc}
\hline Variable & Low & High \\
\hline $\mathrm{HNO}_{3}$ concentration $\left(\mathrm{v} \mathrm{v}^{-1}\right) / \%$ & 0.20 & 1.5 \\
Triton X-114 concentration $\left(\mathrm{v} \mathrm{v}^{-1}\right) / \%$ & 0.10 & 1.0 \\
Sonication time / min & 10 & 60 \\
Breaking temperature $(30 \mathrm{~min}) /{ }^{\circ} \mathrm{C}$ & 50 & 90 \\
\hline
\end{tabular}

Table 3. Two-level fractional factorial design $2^{4-1}$ used in the screening of variables involved in the copper extraction induced by emulsion breaking: experimental matrix and results obtained by its application

\begin{tabular}{lccccc}
\hline Experiment & $\begin{array}{c}\mathrm{HNO}_{3} \\
\text { concentration } \\
\left(\mathrm{v} \mathrm{v}^{-1}\right) / \%\end{array}$ & $\begin{array}{c}\text { Triton X-114 } \\
\text { concentration } \\
\left(\mathrm{v} \mathrm{v}^{-1}\right) / \%\end{array}$ & $\begin{array}{c}\text { Sonication time / } \\
\text { min }\end{array}$ & $\begin{array}{c}\text { Breaking } \\
\text { temperature } /{ }^{\circ} \mathrm{C}\end{array}$ & $\begin{array}{c}\text { Integrated } \\
\text { absorbance }\end{array}$ \\
\hline 1 & 0.20 & 0.10 & 10 & 50 & 0.19769 \\
2 & 1.5 & 0.10 & 10 & 90 & 0.46382 \\
3 & 0.20 & 0.10 & 10 & 50 & 0.8289 \\
4 & 1.5 & 1.0 & 10 & 90 & 0.21203 \\
5 & 0.20 & 0.10 & 60 & 50 & 0.54166 \\
6 & 1.5 & 0.10 & 60 & 50 & 0 \\
7 & 0.20 & 1.0 & 60 & 90 & 0.19814 \\
8 & 1.5 & 1.0 & 35 & 70 & 0.22753 \\
10 & 0.85 & 0.55 & 35 & 70 & 0.22080 \\
11 & 0.85 & 0.55 & 35 & 70 & 0.21423 \\
\hline
\end{tabular}


Table 4. Doehlert matrix used in the optimization of the main variables responsible by the extraction of copper induced by emulsion breaking

\begin{tabular}{lcccc}
\hline Experiment & $\begin{array}{c}\text { Triton } \mathrm{X}-114 \\
\text { concentration }\left(\mathrm{v} \mathrm{v}^{-1}\right) / \%\end{array}$ & $\begin{array}{c}\text { Sonication time } / \\
\text { min }\end{array}$ & $\begin{array}{c}\text { Breaking } \\
\text { temperature } /{ }^{\circ} \mathrm{C}\end{array}$ & $\begin{array}{c}\text { Integrated } \\
\text { absorbance }\end{array}$ \\
\hline 1 & 0.90 & 30 & 75 & 0.44841 \\
2 & 0.70 & 20 & 60 & 0 \\
3 & 0.70 & 20 & 90 & 0.32316 \\
4 & 0.70 & 40 & 60 & 0 \\
5 & 0.70 & 40 & 90 & 0.29152 \\
6 & 0.50 & 10 & 75 & 0.37148 \\
7 & 0.50 & 30 & 75 & 0.36218 \\
8 & 0.50 & 50 & 60 & 0.31097 \\
9 & 0.30 & 20 & 90 & 0 \\
10 & 0.30 & 20 & 60 & 0.47423 \\
12 & 0.30 & 40 & 90 & 0 \\
13 & 0.30 & 40 & 75 & 0.32868 \\
\end{tabular}

Fixed variables: $5.0 \mathrm{~mL}$ for sample volume, $0.2 \%\left(\mathrm{v} \mathrm{v}^{-1}\right)$ for $\mathrm{HNO}_{3}$ concentration, $30 \mathrm{~min}$ for heating time and $10.0 \mathrm{~mL}$ for final volume.

sonication time (ST) between 10 and 50 min and breaking temperature (BT) between 60 and $90{ }^{\circ} \mathrm{C}$. The other parameters were fixed: sample volume at $5.0 \mathrm{~mL}$, the final volume of the mixture at $10.0 \mathrm{~mL}, \mathrm{HNO}_{3}$ concentration at $0.2 \%\left(\mathrm{v} \mathrm{v}^{-1}\right)$ and heating time at $30 \mathrm{~min}$. These volumes were chosen for practicality in the experimental realization. Acid concentration and heating time values were established according to previously published work. ${ }^{3}$

\section{EIEB general procedure obtained after optimization}

To perform the extraction, $5.0 \mathrm{~mL}$ of gasohol was transferred to a $15.0 \mathrm{~mL}$ glass tube, followed by the addition of $100 \mu \mathrm{L}$ of $10 \%\left(\mathrm{v} \mathrm{v}^{-1}\right)$ Triton $\mathrm{X}-114$ surfactant and $200 \mu \mathrm{L}$ of $10 \%\left(\mathrm{v} \mathrm{v}^{-1}\right) \mathrm{HNO}_{3}$. Ultrapure water was added to total $10.0 \mathrm{~mL}$. The top of tube was covered and manually shaken for approximately $30 \mathrm{~s}$. After, this mixture was submitted to sonication using an ultrasonic for $10 \mathrm{~min}$ for the formation of the emulsion, and, subsequently, it was heated at $90{ }^{\circ} \mathrm{C}$ for $30 \mathrm{~min}$ aiming to break the emulsion and phase separation. After the emulsion breaking, a volume of $6.65 \mathrm{~mL}$ of hydroalcoholic solution (aqueous phase) was obtained. The organic phase was discarded using a fine capillary under suction. A volume of $20 \mu \mathrm{L}$ of the aqueous phase was injected into the graphite furnace for the analysis, under the operating conditions described in Table 1.

\section{Results and Discussion}

\section{Pyrolysis and atomization curves}

The thermal behavior of the analyte was evaluated to find the best conditions to optimize the relation between the amount of analyte injected into the graphite furnace and the intensity of the absorbance signal during the HR-CS GF AAS analysis. Figure 1 presents the pyrolysis and atomization behavior for the analyte. For the pyrolysis temperature study, the atomization temperature was set at $2200{ }^{\circ} \mathrm{C}$. The analytical signal increased over the temperature range from 700 to $1100{ }^{\circ} \mathrm{C}$, and, from that latter temperature, the signal decreased greatly indicating loss of analyte in higher temperatures. For the atomization temperature, the pyrolysis temperature was set at $1100^{\circ} \mathrm{C}$. The analytical signal began to remain constant from $2400{ }^{\circ} \mathrm{C}$. Thus, an atomization temperature at $2500{ }^{\circ} \mathrm{C}$ was chosen for the determinations.

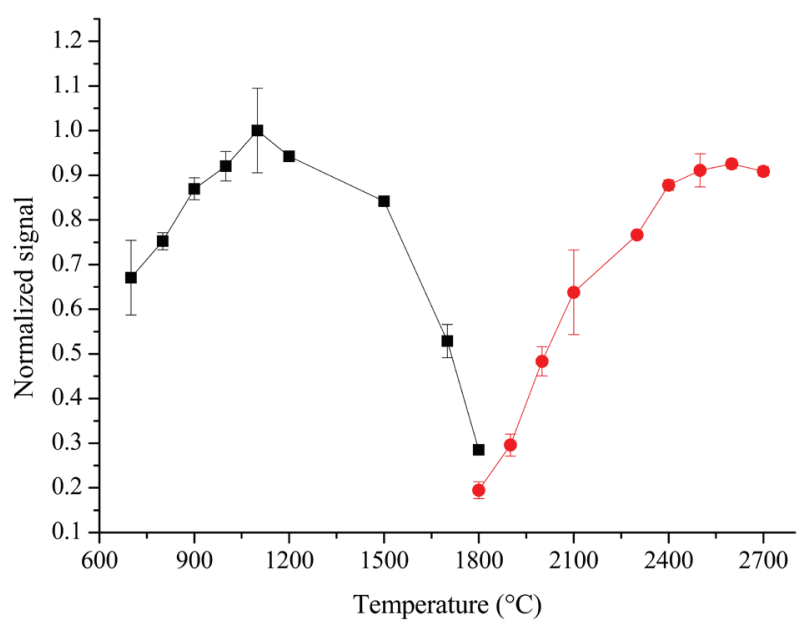

Figure 1. Pyrolysis $(\square)$ and atomization $(\bigcirc)$ curves for $\mathrm{Cu}$ determination in a solution extracted from emulsion breakdown of gasoline after addition of the analyte for a final concentration of $20 \mu \mathrm{g} \mathrm{L} \mathrm{L}^{-1}$. Studies were carried out at a pyrolysis temperature of $1100{ }^{\circ} \mathrm{C}$ and atomization temperature of $2200^{\circ} \mathrm{C}$. 


\section{Optimization steps}

The EIEB is influenced by variables that affect the efficiency of the process demanding that they are optimized. A two-level fractional factorial design was applied to check the significance of the variables in this extraction because it provides information on the factor influences using a small number of experiments, reducing costs and time when compared to full factorial design, without affecting the decision-making capacity and evaluation of results. The variables involved in the study were as follows: Triton $\mathrm{X}-114$ concentration $(\mathrm{SC}), \mathrm{HNO}_{3}$ concentration (AC), sonication time (ST) and temperature for emulsion breaking (BT).

The experimental domain represented by the lower (-1) and upper (+1) values of each variable is presented in Table 2, and the applied experimental matrix is shown in Table 3. In this design, the contrast of the main factors is being deliberately confounded with the contrasts of third-order interactions. Generally, highorder interactions tend not to have significant statistical effects on the process, and so, when confused with a major factor, they can provide information on this factor. Figure 2 shows the Pareto graph and reveals that three variables presented significant effects (within the delimited experimental field) for the extraction. According to this graph, only the breaking temperature presented a positive effect, suggesting that high temperature improves the extraction process. Sonication time and Triton X-114 concentration presented significant effects; however, these effects were negative. This happens because copper ions are not strongly linked to porphyrin groups of the organic fraction of gasoline. Most probably much of the copper content is due to the presence of ethanol that is added to gasoline. The ethanol fraction present in gasohol is easily

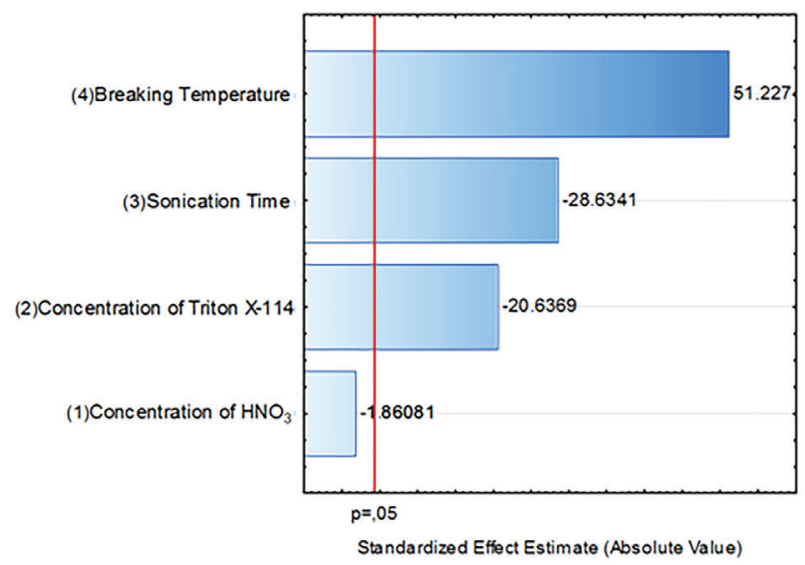

Figure 2. Pareto graph obtained after application of the two-level factorial design $2^{4-1}$, using the emulsion induced extraction in the determination of copper in gasohol. separated even after the addition of only small amounts of $\mathrm{HNO}_{3}$ or surfactant. Although the surfactant has an important role in the extraction procedure, its presence increases the organic load, contributing to the decrease of the analytical signal.

The formation of an emulsion promotes an increase of the contact surface between the organic phase and the hydroalcoholic phase, resulting in a more effective migration of the analyte to the phase of interest. After the emulsion breaks, the surfactant remains almost completely in the hydroalcoholic phase, and, therefore, the increased surfactant concentration contributes to the lowering of the signal due to the increase of organic load. The effect of the breaking temperature (BT) was positive, indicating that an increase in temperature contributes to a better response. It was possible to observe that, in some experiments performed at a breaking temperature equal to 50 or $60{ }^{\circ} \mathrm{C}$, the emulsion breaking did not occur, and, therefore, in the fractional factorial design and Doehlert matrix (Tables 3 and 4, respectively), the absorbance values decrease.

There was a minimum temperature that limits the emulsion to be effectively broken. On the other hand, temperatures above $90{ }^{\circ} \mathrm{C}$ were not possible without disturbance of the system due to the boiling point of the gasoline or possible projections of the sample during the heating. Regarding the effects of the concentrations of surfactant and $\mathrm{HNO}_{3}$, it was observed that low concentrations favored the increase of the signal. The concentration of $\mathrm{HNO}_{3}$ solution was not studied in the Doehlert matrix because it was not significant ( $p$-value $<0.05)$ and was, therefore, fixed at $0.2 \%\left(\mathrm{v} \mathrm{v}^{-1}\right)$.

A Doehlert matrix, generated using five levels each for SC and ST and three levels for BT, is presented with the responses (copper absorbance) in Table 4. A quadratic equation was adjusted to the data aiming to predict the responses $(\mathrm{R})$ behavior and indicate the best copper extraction conditions:

$$
\begin{aligned}
& \mathrm{R}=-5.727( \pm 1.1388)+0.2688( \pm 0.4412) \mathrm{SC}^{2}+ \\
& 0.1009( \pm 0.743) \mathrm{SC}-0.00085( \pm 0.00016) \mathrm{BT}^{2}+ \\
& 0.14716( \pm 0.026) \mathrm{BT}
\end{aligned}
$$

Partial response surfaces were generated. Figure 3 presents the conditions of the variables as a function of the absorbance signal for copper. The optimal conditions that provide the best copper extraction can be observed by analyzing the response surfaces. The obtained optimum values were as follows: $0.1 \%\left(\mathrm{v} \mathrm{v}^{-1}\right)$ for Triton $\mathrm{X}-114$ concentration, $10 \mathrm{~min}$ for sonication time and $90{ }^{\circ} \mathrm{C}$ for breaking temperature. 

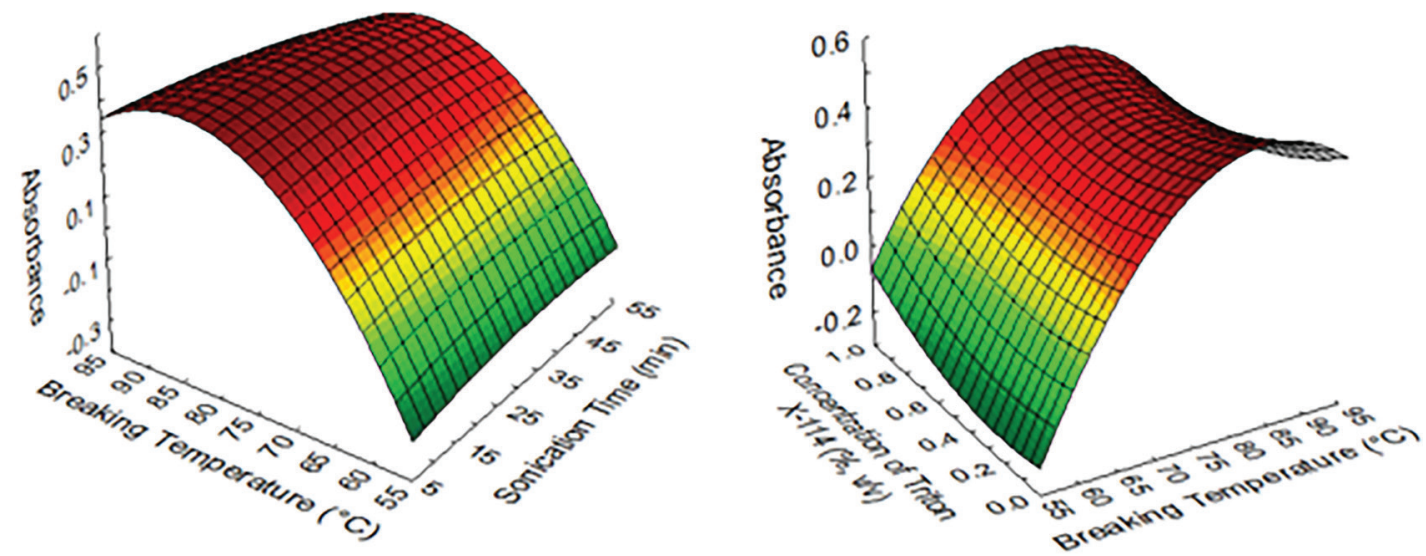

Figure 3. Two partial response surfaces obtained by application of Doehlert design and fitting a quadratic equation to the data set.

Analytical characteristics and application of the developed method

The analytical characteristics of the proposed method were found using the optimal experimental conditions found in the multivariate optimization and in the furnace heating conditions shown in Table 1. Analytical curves for copper were produced and compared using standard solutions ranging from 5.0 to $100 \mu \mathrm{g} \mathrm{L}^{-1}$ in (i) aqueous medium, (ii) emulsion obtained by mixture and sonication of gasohol/surfactant/ $\mathrm{HNO}_{3}$ and ultrapure water, (iii) surfactant only, and (iv) applying the EIEB procedure in the matrix of doped gasohol. In procedure (ii), a real sample of gasohol was used, resulting in calibration by standard addition. Table 5 presents the equations of linear functions of the analytical curves that relate the concentration of the analyte and the response in terms of absorbance and the confidence interval $(\alpha=0.05)$ of the slopes in the different matrices. It was observed that the confidence interval for the values of the slopes obtained by the regression of the curve applied in aqueous medium and EIEB show intercession, demonstrating that the angular coefficients are statistically equal. This fact allows external calibration using aqueous standards, simplifying the proposed method.

The limits of detection (LOD) and the limits of quantification (LOQ) were calculated applying the expressions $\mathrm{LOD}=3 \mathrm{~s} / \mathrm{a}$ and $\mathrm{LOQ}=10 \mathrm{~s} / \mathrm{a}$, in which $\mathrm{a}$ is the analytical curve slope after the EIEB and $s$ is the standard deviation of ten blank signal measurements. The LOD and LOQ found were 0.61 and $2.0 \mu \mathrm{g} \mathrm{L}^{-1}$ respectively. The sensitivity of the method was accessed by the rate of increase of the analytical signal relative to the change in analyte concentration. It can be estimated by the slope of

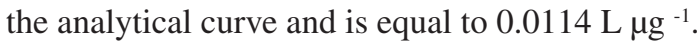

In the proposed procedure, there is a dilution effect, because the final volume of the aqueous phase is greater than the initial volume of the sample. As described in "EIEB general procedure obtained after optimization" sub-section, a sample volume of $5.0 \mathrm{~mL}$ was chosen, and, after the addition of the surfactant and nitric acid solutions, the volume was adjusted to a final volume of $10.0 \mathrm{~mL}$. Considering the $27 \%\left(\mathrm{v} \mathrm{v}^{-1}\right)$ ethanol content in the gasoline samples and its migration to the aqueous phase, an increase in the volume of the aqueous phase is observed, resulting in a small dilution in the phase containing the analyte of interest. This dilution did not affect the determination of copper because HR-CS GFAAS has enough sensitivity to detect this element. In addition, the simplicity in preparing the sample and the high efficiency of the transfer of the analyte from the organic phase to the aqueous phase compensates loss of signal due to dilution. The possibility of using external calibration is a very significant advantage for samples of this nature.

Table 5. Analytical curves obtained in different media for copper aiming the study of matrix effects in GF AAS

\begin{tabular}{|c|c|c|c|}
\hline Matrix & Calibration equation & $\begin{array}{l}\text { Confidence interval of } \\
\text { the slope }{ }^{a} /\left(\mathrm{Abs}_{\left.\mu g^{-1} \mathrm{~L}\right)}\right.\end{array}$ & $\mathrm{R}^{2}$ \\
\hline (i) Aqueous media & $\mathrm{Abs}=0.0120[\mathrm{Cu}]+0.039$ & $0.0108-0.0131$ & 0.9952 \\
\hline (ii) Emulsion & $\mathrm{Abs}=0.00871[\mathrm{Cu}]+0.1942$ & $0.0072-0.0102$ & 0.9847 \\
\hline (iii) Surfactant & $\mathrm{Abs}=0.0081[\mathrm{Cu}]+0.029$ & 0.0069-0.0092 & 0.9889 \\
\hline (iv) Extract from EIEB & Abs $=0.0114[\mathrm{Cu}]+0.0815$ & $0.0095-0.0134$ & 0.9904 \\
\hline
\end{tabular}

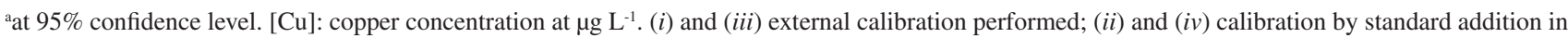
real sample of gasohol. $\mathrm{R}^{2}$ : coefficient of determination; Abs: absorbance; EIEB: extraction induced by emulsion breaking. 
The method precision was investigated and expressed as relative standard deviation (RSD, in percentage) with results of $2.8 \%$ for $10 \mu \mathrm{g} \mathrm{L}^{-1}$ and $1.2 \%$ for $50 \mu \mathrm{g} \mathrm{L}-1(n=8)$. Addition/recovery tests were also performed. Samples of gasohol were doped with 10 and $15 \mu \mathrm{g} \mathrm{L} \mathrm{L}^{-1}$ of copper and analyzed using external calibration. Table 6 presents the copper concentrations for six samples and the recoveries achieved. The developed method allows the copper determination in the gasoline samples at trace levels with an acceptable range of recovery (95-110\%).

Characteristics of the proposed method were compared with other methods published before that included the determination of copper in gasoline samples (Table 7). Among previously published methods, ${ }^{1,10,13,22,23}$ lowest LODs are observed when techniques having no simple approaches were employed, such as electrothermal atomic absorption spectrometry using THFA and ETV-ICP-MS. Thus, the advantages of the developed method are the ability to determine copper in gasoline using a simple sample preparation procedure, the possibility of applying AAS techniques in routine analysis, good LODs and suitable for analysis at trace levels with the ability to use external calibration using standards.

\section{Conclusions}

The proposed analytical method based on extraction induced by emulsion breaking has presented adequate analytical characteristics for separation and subsequent copper determination in gasohol samples by HR-CS GF AAS. The proposed method has presented
Table 6. Determination of copper in Brazilian gasohol by HR-CS GF AAS using the developed method $(\mathrm{n}=3)^{\mathrm{a}}$

\begin{tabular}{|c|c|c|c|}
\hline Sample & $\begin{array}{l}\text { Added / } \\
\left(\mu \mathrm{g} \mathrm{L}^{-1}\right)\end{array}$ & $\begin{array}{l}\text { Concentration / } \\
\left(\mu \mathrm{g} \mathrm{L}^{-1}\right)\end{array}$ & Recovery / \% \\
\hline & 0 & $8.9 \pm 0.2$ & - \\
\hline \multirow[t]{3}{*}{$\mathrm{S} 1$} & 10 & $19.24 \pm 0.04$ & 103 \\
\hline & 15 & $24.05 \pm 0.01$ & 101 \\
\hline & 0 & $20.68 \pm 0.01$ & - \\
\hline \multirow[t]{3}{*}{$\mathrm{S} 2$} & 10 & $31.48 \pm 0.02$ & 108 \\
\hline & 15 & $36.17 \pm 0.03$ & 103 \\
\hline & 0 & $31.9 \pm 0.5$ & - \\
\hline \multirow[t]{3}{*}{ S3 } & 10 & $42.9 \pm 0.2$ & 110 \\
\hline & 15 & $46.7 \pm 0.2$ & 99 \\
\hline & 0 & $14.7 \pm 0.4$ & - \\
\hline \multirow[t]{3}{*}{ S4 } & 10 & $25.4 \pm 0.3$ & 107 \\
\hline & 15 & $29.01 \pm 0.07$ & 95 \\
\hline & 0 & $19.29 \pm 0.08$ & - \\
\hline \multirow[t]{3}{*}{ S5 } & 10 & $29.05 \pm 0.01$ & 98 \\
\hline & 20 & $39.52 \pm 0.04$ & 101 \\
\hline & 0 & $26.46 \pm 0.02$ & - \\
\hline \multirow[t]{2}{*}{ S6 } & 10 & $35.98 \pm 0.02$ & 95 \\
\hline & 20 & $46.80 \pm 0.01$ & 102 \\
\hline
\end{tabular}

${ }^{\mathrm{a}}$ External calibration in aqueous media.

the following advantages: is environmentally friendly, is simple, features low sample preparation cost and operational ease and allows the use of external calibration in aqueous media. In comparison with other methods

Table 7. Comparison among already published methods and the present work for copper (and other metals) determination in fuel samples

\begin{tabular}{|c|c|c|c|c|c|c|}
\hline Analytes & Sample pretreatment & Analytical technique & Calibration & $\mathrm{LOD} /\left(\mu \mathrm{g} \mathrm{L}^{-1}\right)$ & RSD / \% & Reference \\
\hline $\begin{array}{l}\mathrm{Cu}, \mathrm{Cd}, \mathrm{Cr}, \mathrm{Pb} \\
\text { and } \mathrm{Ni}\end{array}$ & direct analysis & THFA & $\begin{array}{l}\text { dilution of the standards } \\
\text { with } n \text {-heptane }\end{array}$ & 0.23 & $5-15$ & 22 \\
\hline $\begin{array}{l}\mathrm{Cu}, \mathrm{Cd}, \mathrm{Fe}, \mathrm{Pb} \\
\text { and } \mathrm{Tl}\end{array}$ & $\begin{array}{l}\text { sample preparation as emulsion } \\
\text { mixing } 1.0 \mathrm{~mL} \text { of gasoline, } \\
0.5 \mathrm{~mL} \text { of concentrated } \mathrm{HNO}_{3} \\
\text { and sonicating for } 5 \mathrm{~min}\end{array}$ & ETV-ICP-MS & $\begin{array}{c}\text { analyte addition isotope } \\
\text { dilution calibration } \\
\text { techniques }\end{array}$ & $\begin{array}{l}2.0 \\
0.6\end{array}$ & - & 1 \\
\hline $\mathrm{Cu}, \mathrm{Fe}, \mathrm{Ni}$ and $\mathrm{Pb}$ & $\begin{array}{l}\text { formation of a three-component } \\
\text { emulsion mixing water, gasoline } \\
\text { and } n \text {-propanol }\end{array}$ & ET AAS & analyte addition & 0.4 & $2-11$ & 23 \\
\hline $\mathrm{Cu}$ & $\begin{array}{l}\text { Moringa oleifera husks as } \\
\text { a biosorbent in an on-line } \\
\text { preconcentration system }\end{array}$ & FAAS & analyte addition & 0.75 & 1.86 & 10 \\
\hline $\mathrm{Cu}, \mathrm{Fe}$ and $\mathrm{Pb}$ & EIEB & HR-CS F AAS & matrix matching method & 3.0 & & 13 \\
\hline $\mathrm{Cu}$ & EIEB & HR-CS GF AAS & external calibration & 0.6 & $1.2-2.8$ & this work \\
\hline
\end{tabular}

LOD: limit of detection; RSD: relative standard deviation; THFA: transverse heated furnace atomizer, ETV-ICP-MS: electrothermal vaporization inductively coupled plasma mass spectrometry, ET AAS: electrothermal atomic absorption spectrometry, FAAS: flame atomic absorption spectrometry, EIEB: extraction induced by emulsion breaking; HR-CS F AAS: high-resolution continuous source flame atomic absorption spectrometry, HR-CS GF AAS: high-resolution continuous source graphite furnace atomic absorption spectrometry. 
based on direct determination, there are simplification of the matrix avoiding more energetic conditions which deteriorate the graphite furnace and improving its analytical characteristics. The multivariate approach allowed the determination of optimal extraction conditions very quickly and efficiently. The use of HR-CS GF AAS allowed the analysis of the elements with the sensitivity required for the level of the metal present in this kind of sample.

\section{Acknowledgments}

This study has been funded mainly by the Coordenação de Aperfeiçoamento de Pessoal de Nível Superior (CAPES, Brazil, finance code 001). The authors also thank to Fundação de Amparo à Pesquisa do Estado da Bahia (FAPESB, Bahia, Brazil), Conselho Nacional de Desenvolvimento Científico e Tecnológico (CNPq, Brazil) and Programa de Formação de Recursos Humanos da ANP PRH/ANP/MCT (PRH/ANP No. 52) for granting subsidies, scholarships and other financial supports.

\section{References}

1. Saint'Pierre, T. D.; Dias, L. F.; Maia, S. M.; Curtius, A. J.; Spectrochim. Acta, Part B 2004, 59, 551.

2. Santos, D. S. S.; Korn, M. G. A.; Guida, M. A. B.; dos Santos, G. L.; Lemos, V. A.; Teixeira, L. S. G.; J. Braz. Chem. Soc. 2011, 22, 552.

3. Souza, V. S.; Teixeira, L. S. G.; Korn, M. G. A.; Cerqueira, U. M. F. M.; Bezerra, M. A.; Fuel 2019, 242, 479.

4. Cunha, F. A. S.; Sousa, R. A.; Harding, D. P.; Cadore, S.; Almeida, L. F.; Araújo, M. C. U.; Anal. Chim. Acta 2012, 727, 34.

5. de Oliveira, M. F.; Saczk, A. A.; Okumura, L. L.; Fernandes, A. P.; de Moraes, M.; Stradiotto, N. R.; Anal. Bioanal. Chem. 2004, 380, 135; Lima, G. L.; Ohara, M. O.; Clausen, D. N.; Nascimento, D. R.; Ribeiro, E. S.; Segatelli, M. G.; Bezerra, M. A.; Tarley, C. R. T.; Microchim. Acta 2012, 178, 61.

6. Rodríguez-Antón, L. M.; Gutíerrez-Martín, F.; Doce, Y.; Fuel 2016, 166, 73.
7. Zhu, Y.; Narukawa, T.; Numata, M.; Kitamaki, Y.; Matsuo, M.; Hioki, A.; Kato, K.; Chiba, K.; Fuel 2013, 103, 736.

8. Novaes, L.; Anchieta, J.; Neto, G.; Mary, N.; Fuel 2012, 99, 9.

9. http://www.anp.gov.br/images/central-de-conteudo/notasestudos-tecnicos/notas-tecnicas/nota-tecnica-gasolinaformulada-fev2018.pdf, accessed in August 2020.

10. do Carmo, S. N.; Damásio, F. Q.; Alves, V. N.; Marques, T. L.; Coelho, N. M. M.; Microchem. J. 2013, 110, 320.

11. Saint'Pierre, T. D.; Dias, L. F.; Pozebon, D.; Aucélio, R. Q.; Curtius, A. J.; Welz, B.; Spectrochim. Acta, Part B 2002, 57, 1991.

12. Cassella, R. J.; Brum, D. M.; Lima, C. F.; Fonseca, T. C. O.; Fuel 2011, 90, 1215.

13. Leite, C. C.; de Jesus, A.; Kolling, L.; Ferrão, M. F.; Samios, D.; Silva, M. M.; Spectrochim. Acta, Part B 2018, 142, 62.

14. Albers, P.; Pietsch, J.; Parker, S. F.; J. Mol. Catal. A: Chem. 2001, 173, 275.

15. Roldan, P. S.; Alcântara, I. L.; Padilha, C. C. F.; Padilha, P. M.; Fuel 2005, 84, 305.

16. Valasques, G. S.; Santos, A. M. P.; Teixeira, L. S. G.; Mata Cerqueira, U. M. F.; Souza, V. S.; Bezerra, M. A.; Appl. Spectrosc. Rev. 2017, 52, 729.

17. Cassella, R. J.; Brum, D. M.; Robaina, N. F.; Lima, C. F.; Fuel 2018, 215, 592.

18. Pereira, F. M.; Zimpeck, R. C.; Brum, D. M.; Cassella, R. J.; Talanta 2013, 117, 32.

19. Viana, C.; Bohrer, D.; Carvalho, L. M.; Nascimento, P. C.; Rosa, M. B.; TrAC, Trends Anal. Chem. 2014, 53, 49.

20. Castro, M. D. L.; Capote, F. P.; Talanta 2007, 72, 321.

21. Instituto Nacional de Metrologia, Qualidade e Tecnologia (Inmetro); Portaria No. 141 de 26 de março de 2019, available at http://www.inmetro.gov.br/legislacao/rtac/pdf/RTAC002553. pdf, accessed in September 2020.

22. Anselmi, A.; Tittarelli, P.; Katskov, D. A.; Spectrochim. Acta, Part B 2002, 57, 403.

23. Campos, R. C.; Santos, H. R.; Grinberg, P.; Spectrochim. Acta, Part B 2002, 57, 15.

Submitted: March 26, 2020

Published online: September 9, 2020 